\title{
Adsorption of $\operatorname{arsenic}(V)$ from aqueous solutions by goethite/silica nanocomposite
}

\author{
R. Attinti ${ }^{1}$ D. Sarkar ${ }^{1}$ K. R. Barrett ${ }^{2}$ R. Datta $^{3}$
}

Received: 19 July 2015/Revised: 3 October 2015 / Accepted: 7 October 2015/Published online: 29 October 2015

(C) Islamic Azad University (IAU) 2015

\begin{abstract}
Silica nanoparticles were synthesized and coated with goethite, creating a nanocomposite. The nanocomposite was tested for removal of arsenic, $\mathrm{As}(\mathrm{V})$, from aqueous solutions. We used scanning electron microscopy (SEM), Fourier transform infrared spectrometry, and a Zetasizer to characterize particle size, surface morphology, functional groups, and surface charge of the nanocomposite. SEM results showed that the size of the synthesized silica nanoparticles ranged from 150 to $250 \mathrm{~nm}$. Batch sorption studies were carried out on the adsorption of $\mathrm{As}(\mathrm{V})$ as a function of $\mathrm{pH}$, contact time, initial concentration, and ionic strength. Maximum adsorption occurred at $\mathrm{pH}$ 3.0. The adsorption capacity did not change significantly with increasing ionic strength. A kinetics study revealed that adsorption of $\mathrm{As}(\mathrm{V})$ by the goethite/silica nanocomposite was rapid: Equilibrium was reached within $120 \mathrm{~min}$. Adsorption kinetics followed a pseudo-second-order kinetic model. The adsorption data were analyzed by both the Langmuir and Freundlich isotherm models. The maximum adsorption capacity of goethite/silica nanocomposite for $\mathrm{As}(\mathrm{V})$ from the Langmuir isotherm was $17.64 \mathrm{mg} \mathrm{g}^{-1}$, which is larger than that of several other adsorbents. The nanocomposite adsorbent showed high efficiency in removing arsenic from aqueous solutions, even at low initial concentrations.
\end{abstract}

D. Sarkar

sarkard@mail.montclair.edu

1 Department of Earth and Environmental Studies, Montclair State University, Montclair, NJ 07043, USA

2 Department of Civil and Environmental Engineering, Manhattan College, Riverdale, NY 10471, USA

3 Department of Biological Sciences, Michigan Technological University, Houghton, MI 49931, USA
Keywords Isotherms - Kinetics - Nanomaterials - Water treatment

\section{Introduction}

Arsenic is a toxic metal as well as a carcinogen linked to numerous forms of skin, lung, liver, bladder, and kidney cancers (Smith et al. 1992). The main source of arsenic is geological activities and anthropogenic activities such as mining, smelting, use of arsenical fertilizers, herbicides and pesticides, and industrial effluents (Smedley and Kinniburgh 2002). Excessive arsenic concentration in source waters used for drinking is a widespread and severe health problem. Ravenscroft et al. (2009) reported "tens of millions of people continue to depend on arsenic-polluted groundwater as a source of drinking water and for irrigation". The problem is especially severe in Bangladesh, Vietnam, China, and India where a significant amount of people are drinking arsenic-contaminated water (Pontinus et al. 1994, Nickson et al. 1998). The United States Environmental Protection Agency (USEPA) and World Health Organization (WHO) have lowered the concentration limit of arsenic in drinking water from 50 to $10 \mu \mathrm{g} \mathrm{L}^{-1}$ (USEPA 2002). The costs incurred to meet this limit are huge: Costs for the USA alone to install and operate arsenic-removal systems have been estimated at several billion US dollars annually (Arrandale 2002). Clearly, cheaper ways to remove arsenic from water are a significant pursuit.

In natural waters, arsenic exists predominantly in inorganic form as arsenite, As(III), and arsenate, $\mathrm{As}(\mathrm{V})$ (Thirunavukkarasu et al. 2001). In aerobic environments, As(III) is thermodynamically unstable and easily converted to $\mathrm{As}(\mathrm{V})$ by oxidizing agents (Van Halem et al. 
2009). Therefore, it is important to develop a reliable, efficient, and low-cost treatment technique for $\mathrm{As}(\mathrm{V})$ removal from water and wastewater. Various treatment methods such as ultrafiltration, ion exchange, coagulation/precipitation, membrane filtration, reverse osmosis, and adsorption have been used for the removal of arsenic from water and wastewater.

Among the above technologies, adsorption is a promising technology due to its high efficiency and costeffectiveness for $\mathrm{As}(\mathrm{V})$ removal (Mohan and Pittaman 2007). Many adsorbents have been reported in the literature for the removal of As(V) such as red mud (Genc-Fuhrman et al. 2004), iron-modified bamboo charcoal (Liu et al. 2012), mesoporous alumina (Han et al. 2013), iron-coated rice husk (Pehlivan et al. 2013), granular activated carbonbased iron-containing adsorbents (Gu et al. 2005), magnesia or manganese-loaded fly ash cenospheres ( $\mathrm{Li}$ et al. 2012), iron-oxide-coated sand (Hsu et al. 2008), natural and iron-modified zeolite (Baskan and Pala 2011), and clays (Wainipee et al. 2013). However, the use of these adsorbents for the removal of $\mathrm{As}(\mathrm{V})$ has some limitations due to the disposable of spent media, technical difficulties for the preparation of these adsorbents, and removal of coexisting ions.

In recent years, nanomaterials have attracted more research attention in water treatment and environmental remediation applications due to their remarkable physical and chemical properties. One of the nanomaterials' properties is that most of the atoms are on the surface and these atoms can bind with other atoms that possess high reactivity. Other properties such as large surface area, higher adsorption capacity, mobility, and catalytic potential make nanomaterials excellent adsorbents for the removal of toxic and heavy metals in water and wastewater.

In recent studies, several nanoscale adsorbents such as cupric oxide (Martinson and Reddy 2009), iron(III) oxide (Prucek et al. 2013), iron-cerium oxide (Basu and Ghosh 2013), magnetite-maghemite (Chowdhury and Yanful 2010), zirconium oxide spheres (Hristovski et al. 2008), maghemite (Tuutijarvi et al. 2009), malachite (Saikia et al. 2011) iron-copper binary oxide (Zhang et al. 2013), titanium dioxide (Valencia-Trejo et al. 2010), and zirconium oxide (Hang et al. 2012) were used to remove $\mathrm{As}(\mathrm{V})$ in aqueous solutions. The authors reported that the abovementioned nanoparticles have a higher surface area and higher adsorption capacity for $\mathrm{As}(\mathrm{V})$. In addition to the direct use of nanoparticles, some researchers studied $\mathrm{As}(\mathrm{V})$ adsorption using $\mathrm{Fe}_{3} \mathrm{O}_{4}$ nanoparticles coated with boron nitride nanotubes (Chen et al. 2011), nano zero-valent iron coated on activated carbon (Zhu et al. 2009), and iron (hydr)oxide nanoparticle-impregnated granular activated carbon (Cooper et al. 2010). The literature survey suggests that iron oxides or iron oxides coated on various solid surfaces have been extensively studied for the removal of $\mathrm{As}(\mathrm{V})$ in aqueous solutions.

Goethite, $\mathrm{FeO}(\mathrm{OH})$, also called bog or brown iron ore, is such an iron oxide mineral. It is widely distributed worldwide and found in abundance in numerous locations around the world (Encyclopedia Britannica 2014). Goethite has been studied as an absorbent for arsenic removal (Chakravarty et al. 2002; Giménez et al. 2007; Lakshmipathiraj et al. 2006; Mamindy-Pajany et al. 2009). Chakravarty et al. (2002) reported it as "major mineral phase" in their "low cost ferruginous manganese ore" which achieved nearly $100 \%$ As removal. A goethite-based adsorbent is sold commercially for As removal under the trade name "E33 Bayoxide", although the cost is high at around 25,000 US\$ per cubic meter (Severn Trent Services 2014).

While goethite nanomaterials have also been studied (Ghosh et al. 2012), to our knowledge, goethite has not been previously applied as a coating to nanomaterials. A recent review article by Trujillo-Reyes et al. (2014) on nanomaterials for water and soil remediation cited the need for more studies related to the topic.

Accordingly, the objectives of this study were to (1) synthesize silica nanoparticles and modify the surface of those particles by coating with goethite, creating a nanocomposite, (2) characterize the surface of the goethite/ silica nanocomposite using various instrumental techniques, and (3) conduct batch experiments to study the effect of $\mathrm{pH}$, contact time, ionic strength, and initial concentration on $\mathrm{As}(\mathrm{V})$ removal. Reaction kinetics and adsorption capacity were also investigated. The work was performed at Montclair State University in Montclair, NJ, USA, during 2010.

\section{Materials and methods}

\section{Materials}

All chemical reagents were of analytical grade obtained from Sigma-Aldrich and Fisher and used without further purification. The water used throughout this study was deionized water, purified with a Milli-Q water purification system. A stock solution of $1000 \mathrm{mg} \mathrm{L}^{-1} \mathrm{As}(\mathrm{V})$ was prepared by dissolving sodium arsenate in deionized water. Working solutions and standards with a desired concentration of $\mathrm{As}(\mathrm{V})$ were prepared from stock solution immediately prior to their use.

\section{Synthesis of goethite/silica nanocomposite}

Silica nanoparticles were synthesized using the procedure from Howard and Khdary (2005) modified slightly. Briefly, $250 \mathrm{~mL}$ of methanol and $250 \mathrm{~mL}$ ammonium hydroxide 
were mixed in a 1-L conical flask for 5 min using a magnetic stirrer. Then, $5 \mathrm{~mL}$ of tetraethoxysilane was slowly added under continuous stirring at $25{ }^{\circ} \mathrm{C}$, and the reaction was left for $1 \mathrm{~h}$. The product was centrifuged for $60 \mathrm{~min}$ at $4000 \mathrm{rpm}$, and the supernatant was removed. The silica was rinsed several times with methanol. Finally, the product was dried under vacuum.

Coating with goethite was performed by adding $5 \mathrm{~g}$ of silica nanoparticles to $25 \mathrm{~mL}$ of solution containing $0.5 \mathrm{~g}$ $\mathrm{Fe}\left(\mathrm{NO}_{3}\right)_{3} \cdot 9 \mathrm{H}_{2} \mathrm{O}$. The $\mathrm{pH}$ of the mixture was increased to $7.0 \pm 0.5$ with $\mathrm{NaOH}$. The mixture was stirred for $1 \mathrm{~h}$, and the solid was separated and washed with deionized water until the $\mathrm{pH}$ of the runoff was constant $(\mathrm{pH}$ 6.0-7.0). The resulting solid was dried at $200{ }^{\circ} \mathrm{C}$ for $6 \mathrm{~h}$ and stored in polystyrene bottle for further use.

\section{Analytical methods}

The particle size and morphology of synthesized silica nanoparticles and goethite/silica nanocomposite were measured by scanning electron microscopy (SEM, Hitachi, S-3400N). The infrared spectrums for analyzing the functional groups in the adsorbent before and after modification were recorded by attenuated total reflectance Fourier transform infrared spectrometry (ATR-FTIR, Thermo Nicolet 4700). The specific surface area of adsorbent was measured by $\mathrm{N}_{2}$ adsorption-desorption isotherm using the Brunauer-Emmett-Teller (BET) method on a Belsorp 28 SA apparatus. Surface charge of the silica nanoparticles and goethite/silica nanocomposite was measured by Zetasizer (Malvern nanoseries). A pH meter (Oakton) calibrated with commercial buffers was used to measure the $\mathrm{pH}$ in samples. A mechanical shaker (Thermo MaxQ) was used for agitating the samples. The concentration of $\mathrm{As}(\mathrm{V})$ in the samples was measured by inductively coupled plasma atomic mass spectrometry (ICP-MS, Thermo $\mathrm{X}$-series). The ICP-MS instrument was equipped with an autosampler, and high-purity argon gas was used to ignite the plasma. The instrument was calibrated with five $\mathrm{As}(\mathrm{V})$ standards; every ten samples, one quality control sample (one of the calibration standards) was injected. The concentration of $\mathrm{As}(\mathrm{V})$ in the solution was always detectable by ICP-MS, so we did not develop any method for $\mathrm{As}(\mathrm{V})$ in this study.

\section{Adsorption studies}

Batch sorption studies were conducted in $50-\mathrm{mL}$ plastic centrifuge tubes. Fifty milligrams of goethite/silica nanocomposite was added to $50-\mathrm{mL}$ tubes, which contain $20 \mathrm{~mL}$ of various concentrations of $\mathrm{As}(\mathrm{V})$ in $0.01 \mathrm{M}$ $\mathrm{NaNO}_{3}$ solution. The $\mathrm{pH}$ was adjusted using $1.0 \mathrm{M} \mathrm{HCl}$ or
1.0 $\mathrm{M} \mathrm{NH}_{4} \mathrm{OH}$, and the tubes were shaken at $200 \mathrm{rpm}$ using a mechanical shaker until they reached the equilibrium. All the adsorption experiments were carried at room temperature. The effect of $\mathrm{pH}(2.0-10.0)$, contact time (0.1-24 h), ionic strength $(0.001-0.25 \mathrm{M})$, and initial concentration (10-75 $\mathrm{mg} \mathrm{L}^{-1}$ ) on the adsorption of $\mathrm{As}(\mathrm{V})$ were studied. After the sorption experiments, the samples were centrifuged. The supernatants were further diluted with $1 \%$ HN03 solution and analyzed by ICP-MS for $\mathrm{As}(\mathrm{V})$ concentration. The amount of arsenic adsorbed was calculated from Eq. (1)

$q=\frac{\left(C_{\mathrm{o}}-C_{\mathrm{e}}\right)}{M / V}$

where $C_{\mathrm{o}}$ and $C_{\mathrm{e}}$ are the initial and equilibrium concentrations of $\mathrm{As}(\mathrm{V})$ in $\mu \mathrm{g} \mathrm{mL}^{-1}, q$ is the $\mathrm{As}(\mathrm{V})$ adsorbed $\left(\mu \mathrm{g} \mathrm{g}^{-1}\right), V$ is the volume of the aqueous solution $(\mathrm{mL})$, and $M$ is the mass of the goethite/silica nanocomposite added to the solution $(\mathrm{g})$.

\section{Results and discussion}

\section{Characterization of nanoparticles and nanocomposite}

The morphologies of synthesized silica nanoparticles and goethite/silica nanocomposite were studied by scanning electron microscopy (SEM). The SEM images in Fig. 1 indicate that the monodispersed particles are spherical in shape. The particle size of the silica nanoparticles and goethite/silica nanocomposite ranged from 150 to $250 \mathrm{~nm}$. Goethite coating onto silica surface did not change the particle size and monodispersity of the original particles (Fig. 1b). Figure 2 shows the FT-IR spectra of silica nanoparticles (Fig. 2a) and goethite/silica nanocomposite (Fig. 2b). The spectral images of silica nanoparticles and goethite/silica nanocomposite are very similar, so we subtracted the spectra to get a difference spectrum to identify new peaks (Fig. 2c). The new peaks at 482 and $915 \mathrm{~cm}^{-1}$ in the subtracted FT-IR spectra confirmed the coating of goethite on the surface of silica nanoparticles, creating a goethite/silica nanocomposite. Additionally, the substitution of iron to silica caused a substantial peak shift of the $\mathrm{Si}-\mathrm{O}-\mathrm{Si}$ stretching band $\left(1067 \mathrm{~cm}^{-1}\right)$ to a lower frequency $\left(994 \mathrm{~cm}^{-1}\right)(\mathrm{Xu}$ and Axe 2005). The new peak at $1107 \mathrm{~cm}^{-1}$ in the subtracted spectra indicates the extended asymmetric stretching of $\mathrm{SiO}_{4}$ in the coated particles.

The surface charge of silica and goethite/silica nanocomposite is shown in Fig. 3. The pH of the points of zero charge $\left(\mathrm{pH}_{\mathrm{PZC}}\right)$ of silica and goethite/silica 

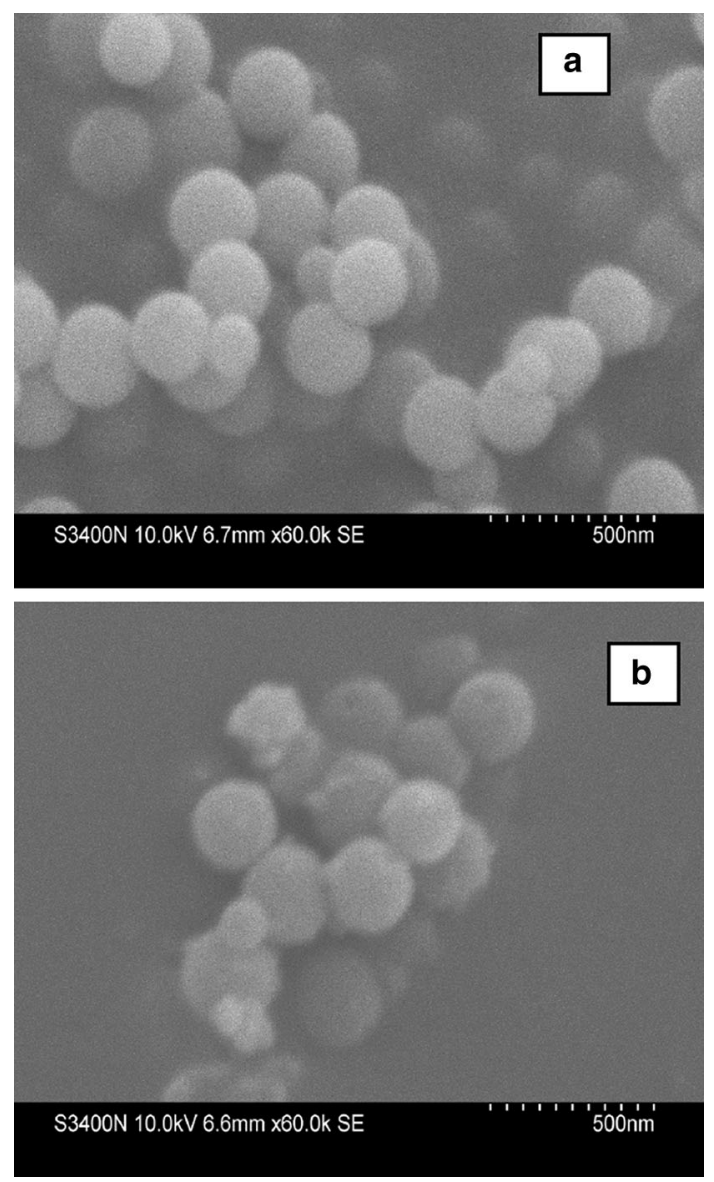

Fig. 1 SEM images of silica nanoparticles (a), and goethite/silica nanocomposite (b)

nanocomposite was 2.5 and 5.9, respectively. The figure clearly shows that silica particles' surface charge was significantly increased after coating with goethite.

The measured BET surface area of silica nanoparticles was $17.2 \mathrm{~m}^{2} \mathrm{~g}^{-1}$, and it enhanced to $78.6 \mathrm{~m}^{2} \mathrm{~g}^{-1}$ after coating the surface with goethite. The new peaks in FT-IR subtraction spectra, surface charge, and surface area increase clearly confirmed the coating of goethite onto the surface of the silica nanoparticles.

\section{Effect of $\mathrm{pH}$ on the adsorption of $\operatorname{As}(\mathrm{V})$}

The effect of $\mathrm{pH}$ on $\mathrm{As}(\mathrm{V})$ adsorption by goethite/silica nanocomposite at an initial $\mathrm{As}(\mathrm{V})$ concentration of $5 \mathrm{mg} \mathrm{L}^{-1}$, fixed ionic strength $(0.01 \mathrm{M} \mathrm{NaNO}$ ), and goethite/silica nanocomposite dose of $2.5 \mathrm{~g} \mathrm{~L}^{-1}$ is shown in Fig. 4. The figure shows that the adsorption of $\mathrm{As}(\mathrm{V})$ by goethite/silica nanocomposite was highly $\mathrm{pH}$ dependent. The experimental solution $\mathrm{pH}$ was measured after the adsorption experiment, and the $\mathrm{pH}$ was similar to the initial value of the solution. The optimal value for $\mathrm{As}(\mathrm{V})$ adsorption was observed in the $\mathrm{pH}$ range 2.0-4.0. Maximum adsorbed amount and removal efficiency of $\mathrm{As}(\mathrm{V})$ were $1.96 \mathrm{mg} \mathrm{g}^{-1}$ and $98.2 \%$, respectively, at pH 3.0 and initial $\mathrm{As}(\mathrm{V})$ concentration of $5.0 \mathrm{mg} \mathrm{L}^{-1}$. Based on the $\mathrm{pH}$ results, we chose $\mathrm{pH} 3.0$ for the rest of the experiments. The $\mathrm{pH}$-dependent behavior of $\mathrm{As}(\mathrm{V})$ adsorption onto goethite/silica nanocomposite was mainly caused by the surface charges of adsorbent and various arsenic species at different $\mathrm{pH}$ values. The predominant $\mathrm{As}(\mathrm{V})$ species exists as negatively charged $\mathrm{H}_{2} \mathrm{AsO}_{4}{ }^{-}$and $\mathrm{HAsO}_{4}{ }^{2-}$ in the $\mathrm{pH}$ range from 2.2 to 11.0. In the experimental study, at $\mathrm{pH} 3.0$ the predominant $\mathrm{As}(\mathrm{V})$ species is $\mathrm{H}_{2} \mathrm{AsO}_{4}{ }^{-}$. The lower adsorption free energy of $\mathrm{H}_{2} \mathrm{AsO}_{4}{ }^{-}$when compared to $\mathrm{HAsO}_{4}{ }^{2-}$ was one of the reasons for favorable $\mathrm{H}_{2} \mathrm{AsO}_{4}{ }^{-}$ adsorption over $\mathrm{HAsO}_{4}{ }^{2-}$ (Chowdhury and Yanful 2010).

The $\mathrm{pH}_{\mathrm{ZPC}}$ of goethite/silica nanocomposite was determined to be 5.9. At $\mathrm{pH}$ below $\mathrm{pH}_{\mathrm{ZPC}}$, the solid adsorbent surface is positively charged, whereas at $\mathrm{pH}$ above $\mathrm{pH}_{\mathrm{ZPC}}$, the solid adsorbent surface is negatively charged. Based on the zeta potential value, goethite/silica nanocomposite' surfaces were positively charged at $\mathrm{pH}$ below 5.9 . Positive charge attracts the $\mathrm{As}(\mathrm{V})$ anions, which resulted in a greater amount of adsorption at acidic $\mathrm{pH}$. Conversely, goethite/silica nanocomposite' surfaces were negatively charged when $\mathrm{pH}$ is above 5.9, resulting in electrostatic repulsion with anionic $\mathrm{As}(\mathrm{V})$. Therefore, the adsorption of $\mathrm{As}(\mathrm{V})$ decreased with increasing $\mathrm{pH}$, and this has been well reported by previous researchers in their work on the adsorption of arsenic by various nanoparticles (Basu and Ghosh 2013; Chowdhury and Yanful 2010; Tuutijarvi et al. 2009; Saikia et al. 2011). In the present study, the main adsorption mechanism between goethite/silica nanocomposite and $\mathrm{As}(\mathrm{V})$ is due to electrostatic attractions.

\section{Effect of ionic strength on the adsorption of $\operatorname{As}(V)$}

To identify the adsorption mechanism of $\mathrm{As}(\mathrm{V})$ onto goethite/silica nanocomposite, the macroscopic technique of evaluating the ionic strength effect on the adsorption was studied, with results illustrated in Fig. 5. The ionic strength was adjusted to $0.01-0.25 \mathrm{M} \mathrm{NaNO}_{3}$ in $20 \mathrm{mg} \mathrm{L}^{-1}$ of $\mathrm{As}(\mathrm{V})$ at $\mathrm{pH}$ 3.0. Increased ionic strength did not have a significant effect on the adsorption of $\mathrm{As}(\mathrm{V})$ onto goethite/ silica nanocomposite, only slightly decreasing the $\mathrm{As}(\mathrm{V})$ adsorption capacity (from 7.85 to $7.48 \mathrm{mg} \mathrm{g}^{-1}$ ) and removal efficiency (from 98.3 to $93.4 \%$ ).

The lack of dependence on ionic strength suggests that the adsorption of $\mathrm{As}(\mathrm{V})$ onto goethite/silica nanocomposite 


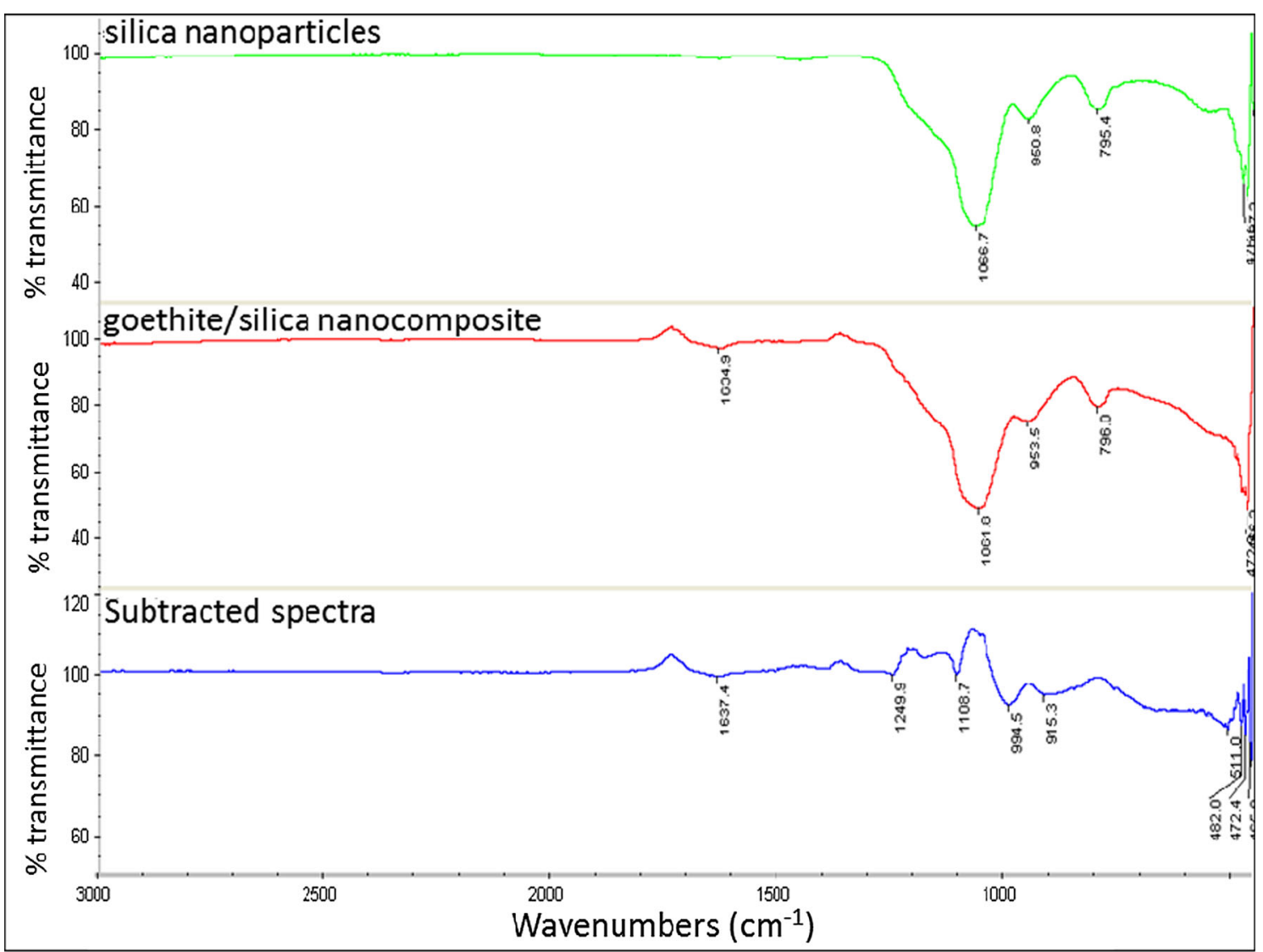

Fig. 2 FT-IR spectra of silica nanoparticles and goethite/silica nanocomposite

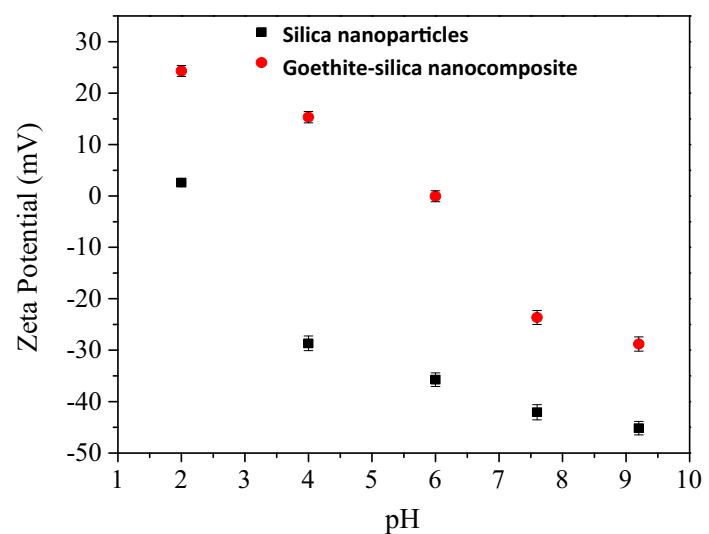

Fig. 3 Zeta potential values of silica and goethite/silica nanocomposite

may be following the inner-sphere complex adsorption mechanism (Hayes et al. 1988). In inner-sphere complexes, the strongly bonded anions do not compete or competed less with the ions of background electrolyte, resulting in a

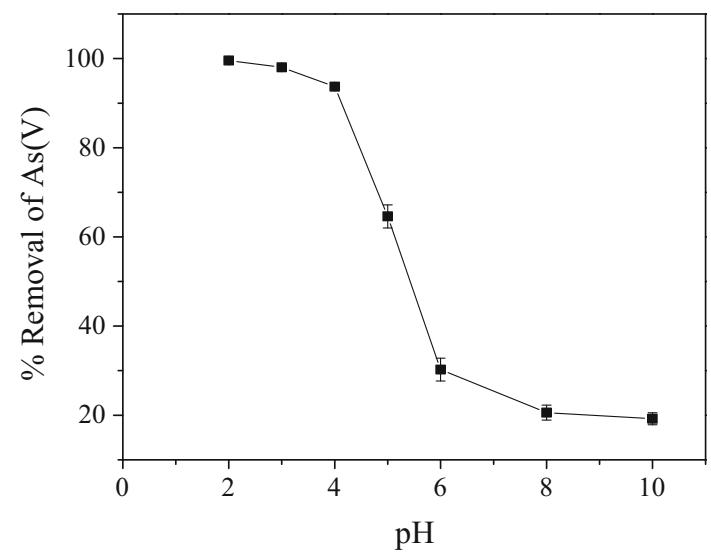

Fig. 4 Effect of $\mathrm{pH}$ on the adsorption of $\mathrm{As}(\mathrm{V})$ onto goethite/silica nanocomposite [initial $\mathrm{As}(\mathrm{V})$ concentration $5 \mathrm{mg} \mathrm{L}^{-1}$, goethite/silica nanocomposite dose $2.5 \mathrm{~g} \mathrm{~L}^{-1}$, and contact time $3 \mathrm{~h}$ ]

greater adsorption. However, in outer-sphere complexes, the anions compete with the ions of an electrolyte solution and the adsorption can be reduced by increasing the background electrolyte concentration. 


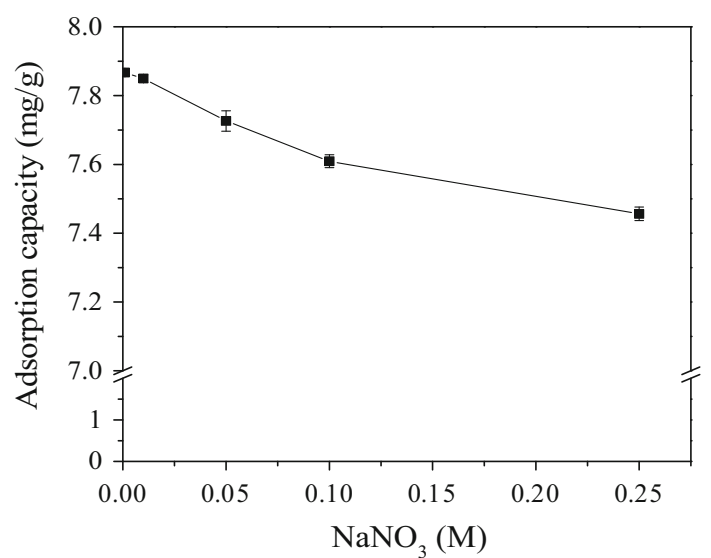

Fig. 5 Effect of ionic strength on the adsorption of $\mathrm{As}(\mathrm{V})$ onto goethite-coated silica nanoparticles [initial $\mathrm{As}(\mathrm{V})$ concentration $20 \mathrm{mg} \mathrm{L}^{-1}$, goethite/silica nanocomposite dose $2.5 \mathrm{~g} \mathrm{~L}^{-1}, \mathrm{pH} 3.0$, and contact time $3 \mathrm{~h}$ ]

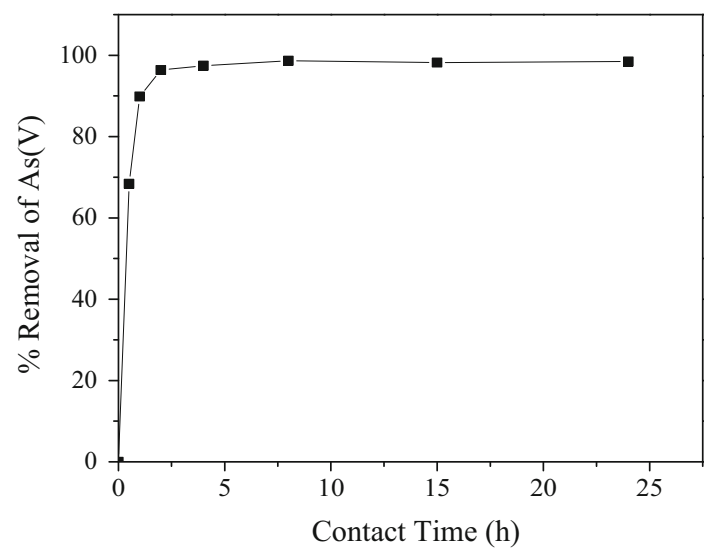

Fig. 6 Effect of contact time on the adsorption of $\mathrm{As}(\mathrm{V})$ by goethite/ silica nanocomposite [initial $\mathrm{As}(\mathrm{V})$ concentration $5 \mathrm{mg} \mathrm{L}^{-1}$, goethite/ silica nanocomposite dose $2.5 \mathrm{~g} \mathrm{~L}^{-1}$, and $\left.\mathrm{pH} 3.0\right]$

\section{Adsorption kinetics}

The kinetics of the adsorption is one of the important characteristics for designing appropriate adsorption technologies. The adsorption of $\mathrm{As}(\mathrm{V})$ onto goethite/silica nanocomposite as a function of contact time at $\mathrm{pH} 3.0$ and initial $\mathrm{As}(\mathrm{V})$ concentration of $5 \mathrm{mg} \mathrm{L}^{-1}$ is presented in Fig. 6. Adsorption was very rapid for the first $60 \mathrm{~min}$ and nearly reached equilibrium after $2 \mathrm{~h}$. As seen from Fig. 6, nearly $50 \%$ removal of $\mathrm{As}(\mathrm{V})$ was observed within 30-min contact time, and the maximum adsorption of $\operatorname{As}(\mathrm{V})$ on goethite/silica nanocomposite was reached in about $2 \mathrm{~h}$.
Hence, in the present study, we used 3-h contact time for further experiments.

To elucidate the adsorption kinetics, the pseudo-firstorder (Lagergren 1898) and pseudo-second-order (Ho and McKay 1998) kinetic models were used to test the experimental data. Because of poor regression coefficient values, the results of the pseudo-first-order kinetic model are not included here. The pseudo-second-order equation can be written as:

$\frac{\mathrm{d} q_{t}}{\mathrm{~d} t}=k_{2}\left(q_{\mathrm{e}}-q_{t}\right)^{2}$

where $k_{2}\left(\mathrm{~g} \mathrm{mg}^{-1} \mathrm{~min}^{-1}\right)$ is the rate constant of adsorption, $q_{\mathrm{e}}$ is the amount of $\mathrm{As}(\mathrm{V})$ adsorbed $\left(\mathrm{mg} \mathrm{g}^{-1}\right)$ at equilibrium, and $q_{t}$ is the amount of the adsorption $\left(\mathrm{mg} \mathrm{g}^{-1}\right)$ at any time $t$. Integrating Eq. (2), using boundary conditions $q_{t}=0$ at $t=0$ and $q_{t}=q_{t}$ at $t=t$ gives

$\frac{t}{q_{t}}=\frac{1}{k_{2} q_{\mathrm{e}}^{2}}+\frac{1}{q_{\mathrm{e}}} t$

The pseudo-second-order rate constant $\left(k_{2}\right)$ and the amount of adsorption at equilibrium $\left(q_{\mathrm{e}}\right)$ were calculated experimentally from intercept and slope of a linear plot $t / q_{t}$ versus $t$ (Fig. 7). The calculated $q_{\mathrm{e}}$ value and the pseudosecond-order rate constant values are $1.976 \mathrm{mg} \mathrm{g}^{-1}$ and $0.1001 \mathrm{~g} \mathrm{mg}^{-1} \mathrm{~min}^{-1}$, respectively. Figure 7 shows that the regression coefficient $\left(R^{2}\right)$ obtained from the pseudosecond-order kinetic model is above 0.999 , which indicates that this kinetic model fits the experimental data accurately.

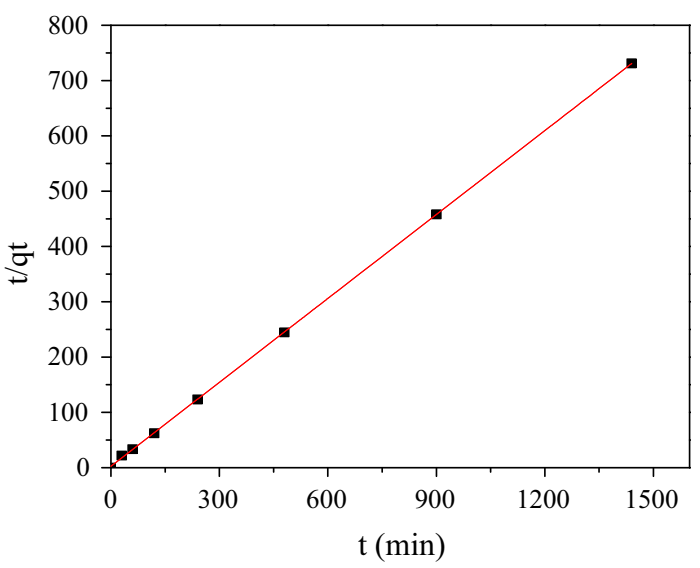

Fig. 7 Pseudo-second-order kinetics for $\mathrm{As}(\mathrm{V})$ adsorption by goethite/silica nanocomposite [initial $\mathrm{As}(\mathrm{V})$ concentration $5 \mathrm{mg} \mathrm{L}^{-1}$, goethite/silica nanocomposite dose $2.5 \mathrm{~g} \mathrm{~L}^{-1}$, and $\mathrm{pH} 3.0$ ] 
Also, the calculated $q_{\mathrm{e}}$ value from the pseudo-second-order kinetic model is very close to experimental $q_{\mathrm{e}}$ value. The high regression coefficient value and good agreement between calculated and experimental $q_{\mathrm{e}}$ values suggested that the adsorption of $\mathrm{As}(\mathrm{V})$ onto goethite/silica nanocomposite follows the pseudo-second-order kinetics. Several authors reported in the literature that the pseudosecond-order kinetic model fit the experimental data accurately on the adsorption of arsenic onto cupric oxide nanoparticles (Reddy et al. 2013), hierarchically porous $\mathrm{CeO}_{2}-\mathrm{ZrO}_{2}$ nanospheres ( $\mathrm{Xu}$ et al. 2013), and ultrafine $\alpha$ $\mathrm{Fe}_{2} \mathrm{O}_{3}$ nanoparticles (Tang et al. 2011).

\section{Adsorption isotherms}

The adsorption isotherms of $\mathrm{As}(\mathrm{V})$ on goethite/silica nanocomposite were conducted using initial metal concentrations ranging from 5 to $75 \mathrm{mg} \mathrm{L}^{-1}$. Two common adsorption isotherms, namely the Langmuir (1918) and the Freundlich (1906), were used to analyze the adsorption data to estimate the maximum adsorption capacity of goethite/silica nanocomposite.

The expression of the Langmuir model is:

$q_{\mathrm{e}}=\frac{q_{m} b c_{\mathrm{e}}}{1+b c_{\mathrm{e}}}$

where $q_{\mathrm{e}}$ is the amount $\left(\mathrm{mg} \mathrm{g}^{-1}\right)$ of $\mathrm{As}(\mathrm{V})$ adsorbed at equilibrium, $c_{\mathrm{e}}$ is the concentration of $\mathrm{As}(\mathrm{V})$ at equilibrium $\left(\mathrm{mg} \mathrm{L}^{-1}\right), q_{m}$ is a Langmuir constant related to maximum adsorption capacity $\left(\mathrm{mg} \mathrm{g}^{-1}\right)$ of $\mathrm{As}(\mathrm{V})$ onto goethitecoated silica nanocomposite, and $b\left(\mathrm{~L} \mathrm{mg}^{-1}\right)$ is a Langmuir constant. A constant separation factor called equilibrium

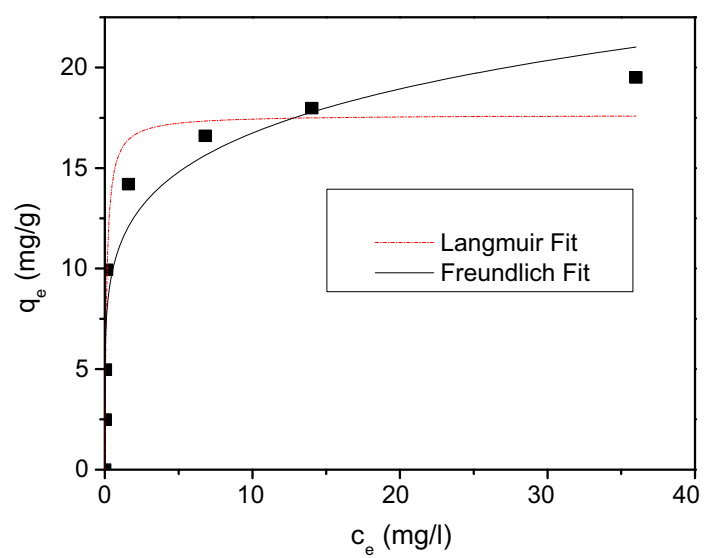

Fig. 8 Adsorption isotherms of As(V) onto goethite/silica nanocomposite [initial $\mathrm{As}(\mathrm{V})$ concentration $5.0-75 \mathrm{mg} \mathrm{L}^{-1}$, goethite/silica nanocomposite dose $2.0 \mathrm{~g} \mathrm{~L}^{-1}, \mathrm{pH} 3.0$, and contact time $3 \mathrm{~h}$ ] parameter, $R_{\mathrm{L}}$, was calculated from the following equation to check whether the adsorption is favorable or unfavorable.

$R_{\mathrm{L}}=\frac{1}{1+b c_{\mathrm{o}}}$

where $b$ is the Langmuir constant and $c_{\mathrm{o}}$ is the initial concentration of $\mathrm{As}(\mathrm{V})$. For a favorable adsorption process, $0<R_{\mathrm{L}}<1$.

The Freundlich model is expressed as:

$q_{\mathrm{e}}=k_{f} c_{\mathrm{e}}^{1 / n}$

where $q_{\mathrm{e}}$ is the amount $\left(\mathrm{mg} \mathrm{g}^{-1}\right)$ of $\mathrm{As}(\mathrm{V})$ adsorbed at equilibrium, $c_{\mathrm{e}}$ is the concentration of $\mathrm{As}(\mathrm{V})$ at equilibrium $\left(\mathrm{mg} \mathrm{L}^{-1}\right), k_{\mathrm{f}}$ is a Freundlich constant related to adsorption capacity, and $\mathrm{n}$ is a dimensionless Freundlich constant.

Figure 8 shows the experimental data fit with the Langmuir and Freundlich isotherms. The best-fit values of the parameters were $q_{m}=17.64 \mathrm{mg} \mathrm{g}^{-1}$ and $b=8.31 \mathrm{~L} \mathrm{mg}^{-1}$ for the Langmuir isotherm and $k_{\mathrm{f}}=11.12$ and $n=5.62$ for the Freundlich isotherm. The $R^{2}$ values for the fit of the data for the two isotherms were 0.97 and 0.92 , respectively, indicating that the experimental data were better fit by the Langmuir isotherm than by the Freundlich isotherm. The regression data obtained from both isotherms suggest that $\mathrm{As}(\mathrm{V})$ adsorption onto goethite/silica nanocomposite is dominated by a monolayer adsorption process. The maximum sorption capacity of goethite/silica nanocomposite for $\mathrm{As}(\mathrm{V})$ estimated by the Langmuir adsorption isotherm model was $17.64 \mathrm{mg} \mathrm{g}^{-1}$. The $R_{\mathrm{L}}$ value for $\mathrm{As}(\mathrm{V})$ is 0.012 at the initial concentration of $10 \mathrm{mg} \mathrm{L}^{-1}$. This suggested that the adsorption of $\mathrm{As}(\mathrm{V})$ onto goethite/silica nanocomposite was favorable.

Table 1 summarizes the maximum adsorption capacities of goethite/silica nanocomposite and other adsorbents for As $(\mathrm{V})$ removal. This table compares the maximum adsorption capacity of goethite/silica nanocomposite with that of other nanoparticles reported in the literature, as calculated from Langmuir isotherm. In the other sorption studies, the researchers optimized the $\mathrm{pH}$ and mass of adsorbent for the removal of arsenic, similar to what was done in this study. Likewise, they also used wide range of initial As concentration adsorption data to calculate the maximum adsorption capacity. The results in Table 1 indicate that goethite/silica nanocomposite provided higher adsorption capacity for $\mathrm{As}(\mathrm{V})$ removal than several other adsorbents reported in the literature. The variations in adsorption capacities of various adsorbents for $\mathrm{As}(\mathrm{V})$ removal are mainly dependent on adsorbent surface properties. 
Table 1 Maximum adsorption capacities of various adsorbents for $\mathrm{As}(\mathrm{V})$ removal

\begin{tabular}{lll}
\hline Adsorbent & Adsorption capacity $\left(\mathrm{mg} \mathrm{g}^{-1}\right)$ & References \\
\hline Micro/nanostructured $\mathrm{MnO}_{2}$ spheres & 14.50 & Zhang and Sun (2013) \\
Ascorbic acid-coated $\mathrm{Fe}_{3} \mathrm{O}_{4}$ nanoparticles & 16.56 & Feng et al. (2012) \\
Commercial maghemite & 16.70 & Tuutijarvi et al. (2009) \\
Nano zero-valent iron-coated activated carbon & 12.0 & Zhu et al. (2009) \\
Iron (III)-modified natural zeolite tuff & 1.55 & Stanic et al. (2009) \\
Cupric oxide nanoparticles & 22.6 & Martinson and Reddy (2009) \\
Anatase nanoadsorbent & 16.98 & Kocanas-Atakl and Yurum (2013) \\
$\mathrm{Zr}$-loaded resin & 11.28 & Li et al. (2013) \\
TiO & 11.53 & Valencia-Trejo et al. (2010) \\
$\mathrm{Goethite}_{2}$ silica nanocomposite & 17.64 & This work \\
\hline
\end{tabular}

\section{Conclusion}

A novel goethite/silica nanocomposite was shown to be an efficient adsorbent for the removal of As(V). SEM, FT-IR, Zetasizer, and surface area analyzer data confirmed the synthesis and goethite coating onto silica nanoparticles. The preparation of the modified silica nanoparticles is very simple and low cost when compared to other commercially available sorbents in the market. The $\mathrm{As}(\mathrm{V})$ adsorption is highly $\mathrm{pH}$ dependent, and the optimal $\mathrm{pH}$ was around 3.0. The increase in ionic strength did not show any significant influence on the adsorption of $\mathrm{As}(\mathrm{V})$ onto goethite/silica nanocomposite. The kinetic data showed that the adsorption was rapid, $50 \%$ removal of $\mathrm{As}(\mathrm{V})$ was obtained within 30-min contact time, and the equilibrium was reached within $2 \mathrm{~h}$. The adsorption kinetics followed the pseudo-second-order kinetic model. The data of As(V) adsorption onto goethite/silica nanocomposite were well fit with the Langmuir isotherm, and the maximum adsorption capacity was found to be $17.64 \mathrm{mg} \mathrm{g}^{-1}$, which is higher than that of several other adsorbents. To assess the practical applicability of the adsorbent, further study is needed, for example, on its hydraulic properties and its cost to manufacture.

Acknowledgments The authors would like to acknowledge Mr. Kevin Olsen, Department of Chemistry, Montclair State University, Montclair, NJ, for recording the FT-IR spectra of adsorbents.

\section{References}

Arrandale T (2002) EPA, the arsenic dictator. Governing 15:80

Baskan MB, Pala A (2011) Removal of arsenic from drinking water using modified natural zeolite. Desalination 281:396-403
Basu T, Ghosh UC (2013) Nanao-structured iron(III)-cerium(IV) mixed oxide: synthesis, characterization and arsenic sorption kinetics in the presence of co-existing ions aiming to apply for high arsenic ground water treatment. Appl Surf Sci 283:471-481

Chakravarty S, Dureja V, Bhattacharyya G, Maity S, Bhattacharjee S (2002) Removal of arsenic from groundwater using low cost ferruginous manganese ore. Water Res 36:625-632

Chen R, Zhi C, Yang H, Bando Y, Zhang Z, Sugiur N, Golberg D (2011) Arsenic (V) adsorption on $\mathrm{Fe}_{3} \mathrm{O}_{4}$ nanoparticle-coated boron nitride nanotubes. J Colloid Interface Sci 359:261-268

Chowdhury SR, Yanful EK (2010) Arsenic and chromium removal by mixed magnetite-maghemite nanoparticles and the effect of phosphate on removal. J Environ Manage 91:2238-2347

Cooper AM, Hristovski KD, Moller T, Westerhoff P, Sylvester P (2010) The effect of carbon type on arsenic and trichloroethylene removal capabilities of iron (hydr)oxide nanoparticle-impregnated granular activated carbons. J Hazard Mater 183:381-388

Encyclopedia Britannica (2014) Goethite. In: Encyclopedia Britannica Online. Retrieved 23 Nov 2014 from http://www.britannica. com/EBchecked/topic/237093/goethite

Feng L, Cao M, Ma X, Zhu Y, Hu C (2012) Super paramagnetic high surface area $\mathrm{Fe}_{3} \mathrm{O}_{4}$ nanoparticles as adsorbents for arsenic removal. J Hazard Mater 217-218:436-439

Freundlich H (1906) Uber die adsorption in losungen. Z Phys Chem $57: 387-470$

Genc-Fuhrman H, Tjell JC, McConchie D (2004) Adsorption of arsenic from water using activated neutralized red mud. Environ Sci Technol 38:2428-2434

Ghosh M, Eddy G, Poinern J, Issa TB, Singh P (2012) Arsenic adsorption on goethite nanoparticles produced through hydrazine sulfate assisted synthesis method. Korean $J$ Chem Eng 29:95-102

Giménez J, Martinez M, de Pablo J, Rovira M, Duro L (2007) Arsenic sorption onto natural hematite, magnetite, and goethite. J Hazard Mater 141:575-580

Gu Z, Fang J, Deng B (2005) Preparation and evaluation of GACbased iron-containing adsorbents for arsenic removal. Environ Sci Technol 39:3833-3843

Han C, Li H, Pu H, Yu H, Deng L, Huang S, Luo Y (2013) Synthesis and characterization of mesoporous alumina and their performances for removing arsenic(V). Chem Eng J 217:1-9 
Hang C, Li Q, Gao S, Shang JK (2012) As(III) and As(V) adsorption by hydrous zirconium oxide nanoparticles synthesized by a hydrothermal process followed with heat treatment. Ind Eng Chem Res 51:353-361

Hayes KF, Papelis C, Leckie JO (1988) Modeling ionic strength effects on anion adsorption at hydrous oxide/solution interfaces. J Colloid Interface Sci 125:717-726

Ho YS, McKay G (1998) Sorption of dye from aqueous solution by peat. Chem Eng J 70:115-124

Howard AG, Khdary NH (2005) Nanoscavenger based dispersion preconcentration; sub-micron particulate extractants for analyte collection and enrichment. Analyst 130:1432-1438

Hristovski K, Westerhoff PK, Crittenden JC, Olson LW (2008) Arsenate removal by nanostructured $\mathrm{ZrO}_{2}$ spheres. Environ Sci Technol 42:3786-3790

Hsu JC, Lin CJ, Liao CH, Chen ST (2008) Removal of As(V) and As(III) by reclaimed iron-oxide coated sands. J Hazard Mater 153:817-826

Kocanas-Atakl ZO, Yurum Y (2013) Synthesis and characterization of anatase nanoadsorbent and application in removal of lead, copper and arsenic from water. Chem Eng J 225:625-635

Lagergren S (1898) Zur theorie der sogenannten adsorption geloster stoffe, Kungliga Svenksa Vetenskapsakademiens. Handlingar 24:1-39

Lakshmipathiraj P, Narasimhan BRV, Prabhakar S, Raju GB (2006) Adsorption of arsenate on synthetic goethite from aqueous solutions. J Hazard Mater 136:281-287

Langmuir I (1918) The adsorption of gases on plane surface glass, mica and platinum. J Am Chem Soc 40:1361-1368

Li Q, Xu XT, Cui H, Pang J, Wei ZB, Sun Z, Zhai J (2012) Comparison of two adsorbents for the removal of pentavalent arsenic from aqueous solutions. J Environ Manag 98:98-106

Li C, Xu W, Jia D, Liu X (2013) Removal of arsenic from drinking water by using the Zr-loaded resin. J Chem Eng Data $58: 427-435$

Liu X, Ao H, Xiong X, Xiao J, Liu J (2012) Arsenic removal from water by iron-modified bamboo charcoal. Water Air Soil Pollut 223:1033-1034

Mamindy-Pajany Y, Hurel C, Marmier N, Roméo M (2009) Arsenic adsorption onto hematite and goethite. C R Chim 12:876-881

Martinson CA, Reddy KJ (2009) Adsorption of arsenic (III) and arsenic (V) by cupric oxide nanoparticles. J Colloid Interface Sci 336:406-411

Mohan D, Pittaman CU (2007) Arsenic removal from water and wastewater using adsorbents-a critical review. J Hazard Mater 142:1-53

Nickson R, McArthur J, Burgess W, Ahmed KM, Ravenscroft P, Rahman M (1998) Arsenic poisoning of Bangladesh ground water. Nature 395:338

Pehlivan E, Tran TH, Ouedraogo WKI, Schmidt C, Zachmann D, Bahadir M (2013) Removal of As(V) from aqueous solutions by iron coated rice husk. Fuel Process Technol 106:511-517

Pontinus FW, Brown KG, Chen CJ (1994) Health implications of arsenic in drinking water. J Am Water Works Assoc 86:52-63

Prucek R, Tucek J, Kolarik J, Filip J, Marusak Z, Sharma VK, Zboril R (2013) Ferrate(VI)-induced arsenite and arsenate removal by in situ structural incorporation into magnetic iron(III) oxide nanoparticles. Environ Sci Technol 47:3283-3292
Ravenscroft P, Brammer H, Richards K (2009) Arsenic pollution: a global synthesis. Wiley, London

Reddy KJ, McDonald KJ, King H (2013) A novel arsenic removal process for water using cupric oxide nanoparticles. J Colloid Interface Sci 397:96-102

Saikia J, Saha B, Das G (2011) Efficient removal of chromate and arsenate from individual and mixed system by malachite nanoparticles. J Hazard Mater 186:575-582

Severn Trent Services (2014) Arsenic Removal Media-Bayoxide ${ }^{\circledR}$. Severn Trent Services. Retrieved 23 Nov 2014 from https:// www.severntrentservices.com/Drinking_Water_Treatment_ Inorganic_Removal_Systems/Arsenic_Removal_Media_ Bayoxide_prod_589.aspx

Smedley PL, Kinniburgh DG (2002) A review of the source, behavior and distribution of arsenic in natural waters. Appl Geochem 17:517-568

Smith AH, Hopenhayn-Rich C, Bates MN, Goeden HM, HertzPicciotto I, Duggan HM, Wood R, Kosnett MJ, Smith MT (1992) Cancer risks from arsenic in drinking water. Environ Health Perspect 97:259-267

Stanic T, Dakovic A, Zivanovic A, Tomasevic-Xanovic M, Dondur V, Milicevic S (2009) Adsorption of arsenic (V) by iron (III)modified natural zeolite tuff. Environ Chem Lett 7:161-166

Tang W, Li Q, Gao S, Shang JK (2011) Arsenic (III, V) removal from aqueous solution by ultra $\alpha-\mathrm{Fe}_{2} \mathrm{O}_{3}$ nanoparticles synthesized from solvent thermal method. J Hazard Mater 192:131-138

Thirunavukkarasu OS, Viraraghavan T, Subramanian KS (2001) Removal of arsenic in drinking water by iron oxide-coated sand and ferrihydrite-batch studies. Water Qual Res J Can 36:55-70

Trujillo-Reyes J, Peralta-Videa JR, Gardea-Torresdey JL (2014) Supported and unsupported nanomaterials for water and soil remediation: are they a useful solution for worldwide pollution? J Hazard Mater 280:487-503

Tuutijarvi T, Lu J, Sillanpaa M, Chen G (2009) As(V) adsorption on maghemite nanoparticles. J Hazard Mater 166:1415-1420

USEPA (2002) Federal Register, vol 67, pp 78203-78209

Valencia-Trejo E, Valencia-Mendez M, Alfardo-Cueas-Villanueva R, Garnica-Romo MG, Cortes-Martinez R (2010) Effect of temperature on the removal of arsenate from aqueous solutions by titanium dioxide nanoparticles. J Appl Sci Environ Sanit 5:171-184

Van Halem D, Heijman SGJ, Amy GL, van Dijk JC (2009) Subsurface arsenic removal for small-scale application in developing countries. Desalination 248:241-248

Wainipee W, Cuadros J, Sephton MA, Unsworth C, Gill MG, Strekopytov S, Weiss DJ (2013) The effects of oil on As(V) adsorption on illite, kaolinite, montmorillonite and chlorite. Geochim Cosmochim Acta 121:487-502

$\mathrm{Xu} \mathrm{Y,} \mathrm{Axe} \mathrm{L} \mathrm{(2005)} \mathrm{Synthesis} \mathrm{and} \mathrm{characterization} \mathrm{of} \mathrm{iron-oxide}$ coated silica and its effect on metal adsorption. J Colloid Interface Sci 282:11-19

Xu W, Wang J, Wang L, Sheng G, Liu J, Yu H, Huang XJ (2013) Enhanced arsenic removal from water by hierarchically porous $\mathrm{CeO}_{2}-\mathrm{ZrO}_{2}$ nanospheres: role of surface- and structure-dependent properties. J Hazard Mater 260:498-507

Zhang T, Sun DD (2013) Removal of arsenic from water using multifunctional micro-/nano-structured $\mathrm{MnO}_{2}$ spheres and microfiltration. Chem Eng J 225:271-279 
Zhang G, Ren Z, Zhang X, Chen J (2013) Nanostructured iron(III)copper(II) binary oxide: a novel adsorbent for enhanced arsenic removal from aqueous solutions. Water Res 47:4022-4031
Zhu H, Jia Y, Wu X, Wang H (2009) Removal of arsenic from water by supported nano zero-valent iron on activated carbon. J Hazard Mater 172:1591-1596 